ISBN 978-81-933894-1-6

International Conference on Arts, Social Sciences, History and Interdisciplinary Studies

(ASSHIS-2017)

Kyoto (Japan) April 20-21, 2017

\title{
Factors that Influence Consumer Behavior in Buying Accessories
}

\author{
Dr. Chairat Suriyaapha, Miss Yang Qiu \\ Posgauat school of business administration \\ Kasembundit University \\ arjarnchairat@gmail.com
}

\begin{abstract}
The study about buying behavior for accessories has aims to evaluate influences of marketing mix on buying decision of customers and to study buying behavior of customers for accessories. This is a quantitative research having independent variables including gender, age, marital status, education, monthly income, and number of accessories owned as well as marketing mix including product, price, place, and promotion. Dependent variable is consumer buying behavior for accessories. Questionnaires were used as tools for the study. The research used percentage, mean, standard deviation, Chi-square analysis, and regression analysis as statistical tools.

The study revealed that most of questionnaire respondents were female aged 20-29, single, graduated Bachelor's degree, earning 30,000-40,000 Baht per month. Most of them have 10 pieces of accessories and continue to use for 3-4 years. The reason for the purchase is for beauty, family member has influence in the purchase as well as passion and value, frequency to buy accessories is on average 3 times a year, the purchase is done at shop near the house, mostly purchase by oneself, and each purchase costs about 2,001-3,000 Baht.

The study recommends that for product, sellers should focus on quality and variety of products, packaging should be attractive and durable. For price, sellers should make various modes of payment available. For distribution channel, sellers should add delivery service. For promotion, sellers should communicate with customers through various types of media such as television and leaflet. For promotion, sellers should promote volume discount, free gifts and premiums as well as train personnel to have thorough knowledge about the products.
\end{abstract}

Keyword: influence consumer

\section{Background and Significance of the Study}

Accessories are one of cultural identity being used along with clothing. In ancient times, people decorate their bodies with tattoo or painting on their skin. The first skin painting was found in Egypt about 2,000 years B.C. The word "Sak" in Thai means "tattoo" in English, and the word tattoo derives from Haiti language "Tatau" which has meaning about marking anything on the body including decoration with gold. Gold was evidenced for being used as accessories in Egyptian and Ancient Greek era. Accessories are one of materials that reveal culture in a history. They are the signs that can tell about culture, custom, and habit of their wearers. Studies about historical arts often include the studies about accessories along the side since apart from decoration for beauty accessories can also indicate status of people. For example, Native Americans traditionally use paint or feather to decorate their bodies and the decorations imply positions as well as wealth of wearers.

Accessories are important component for woman's dressing from the past until present. No nation in the world can refuse beauty of accessories. There are different types and styles of accessories for people to choose to 
match their personalities and dresses they wear. Accessories can be grouped into 2 main categories one is gems $\&$ jewelry and the other is made of cloth or other materials used for dressing such as gloves and bags. Whether they are for men or women, accessories help to improve personalities of people. They help to enhance wearers' image and confidence as in a saying "Fine feathers make find birds." Accessories reflect emotion and idea of people. Accessories make people love themselves and be proud when they wear, and such accessories need not be expensive. More important things are matching and fitness. For accessories selection, attention should be paid to gems $\&$ jewelry that are easy to take care and suitable for many occasions. If it is diamond, one should choose the design that is not easily outdated. Women may consider wearing earrings, ring, brooch, and bracelet that are all together look nice and not too much. Men may use tie pin that is made of diamond and simple in design along with cufflinks for different occasions.

Accessories, apart from being used for beauty, are used to cure sickness such as healing stones which are known and used for long time since the past. They are processed into accessories form for easier use such as necklace, bracelet, ring, and earrings. Wearers of these healing stones personally believe that they can improve their health wearing these accessories.

From the above information, the author became interested to study Bangkok consumer behavior in buying accessories so that the results can be used to help improve selling of accessories to match customer needs.

\section{Research Objective}

To study Bangkok consumer behavior in purchasing accessories.

To study factors that affect Bangkok consumer behavior in purchasing accessories

Independent Variables

Dependent Variable

Demographic Factors
- Gender- Age- Marital Status- Education Level
- Monthly Income- Number of Accessories
Owned

Marketing Mix

- Product- Price- Place- Promotion



Mean (3.35)

Fig. 4.19: Marketing mix 


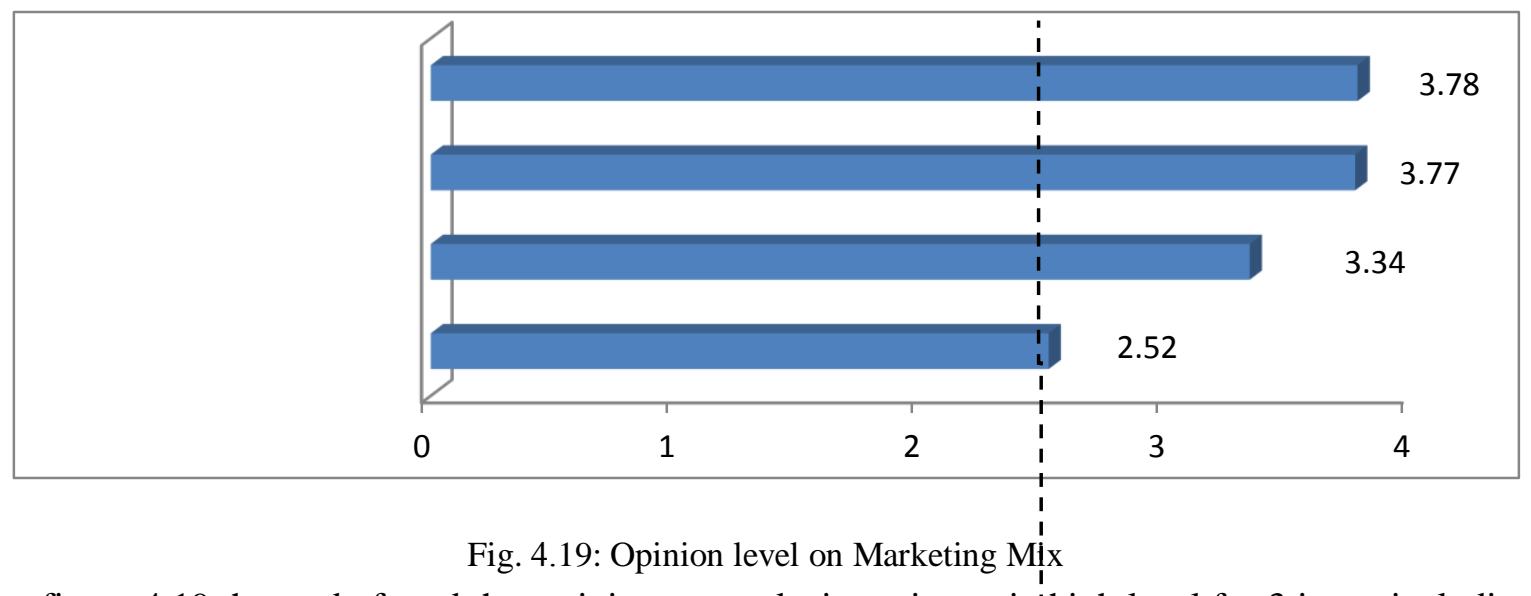

From figure 4.19 the study found that opinion on marketing mix are in' high level for 3 items including Place $(\overline{\mathrm{X}}=3.78)$, Promotion $(\overline{\mathrm{X}}=3.77)$, and Price $(\overline{\mathrm{X}}=3.34)$. Low level of opipion was found in Product $(\overline{\mathrm{X}}=2.52)$. Overall opinion on marketing mix was in medium level $(\overline{\mathrm{X}}=3.35)$.

TABLE 4.7: Indicates Relationship Between Marketing Mix And Buying Behavior For Accessories.

\begin{tabular}{|c|c|c|c|c|c|c|}
\hline \multirow{2}{*}{ Marketing Mix } & \multicolumn{2}{|c|}{$\begin{array}{l}\text { Unstandardized } \\
\text { Coefficients }\end{array}$} & \multirow[t]{2}{*}{$\begin{array}{l}\text { Standardized } \\
\text { Coefficients }\end{array}$} & \multirow{2}{*}{$\mathrm{t}$} & \multirow{2}{*}{ Sig. } & \multirow{2}{*}{ Results } \\
\hline & $\mathrm{B}$ & $\begin{array}{l}\text { Std. } \\
\text { Error }\end{array}$ & & & & \\
\hline $\begin{array}{l}\text { (Constant) } \\
\text { Product }\end{array}$ & 0.06 & 0.25 & & 0.241 & 0.81 & \\
\hline 1. Valuable product. & 0.045 & 0.087 & 0.029 & 0.522 & 0.603 & Unrelated \\
\hline 2. Nice color and size. & 0.1 & 0.096 & 0.063 & 0.043 & 0.299 & Unrelated \\
\hline 3. Famous brand. & 0.009 & 0.086 & 0.005 & 0.102 & 0.919 & Unrelated \\
\hline $\begin{array}{l}\text { 4. Information about composition of } \\
\text { accessories is well specified. }\end{array}$ & 0.108 & 0.119 & 0.065 & 0.905 & 0.368 & Unrelated \\
\hline $\begin{array}{l}\text { 5. Details about special features of product } \\
\text { is well informed. }\end{array}$ & 0.038 & 0.099 & 0.023 & 0.381 & 0.704 & Unrelated \\
\hline $\begin{array}{l}\text { 6. Accessories analysis results are shown } \\
\text { on the package. }\end{array}$ & 0.027 & 0.096 & 0.016 & 0.276 & 0.783 & Unrelated \\
\hline 7. Accessories are imported products. & 0.089 & 0.095 & 0.053 & 0.937 & 0.351 & Unrelated \\
\hline 8. Packages are colorful and nice. & 0.164 & 0.106 & 0.1 & 0.544 & 0.126 & Unrelated \\
\hline 9. Packages are durable. & 0.033 & 0.101 & 0.021 & 0.326 & 0.746 & Unrelated \\
\hline $\begin{array}{l}\text { 10. The product suits with character of } \\
\text { wearer. }\end{array}$ & 0.287 & 0.103 & 0.179 & 0.777 & $0.007^{*}$ & Related \\
\hline
\end{tabular}




\begin{tabular}{|c|c|c|c|c|c|c|}
\hline Price & & & & & & \\
\hline 1. Reasonable price. & 0.009 & 0.057 & 0.01 & 0.163 & 0.871 & Unrelated \\
\hline 2. Clear price tags are shown. & 0.005 & 0.061 & 0.006 & -0.08 & 0.936 & Unrelated \\
\hline $\begin{array}{l}\text { 3. Special price for newly launched } \\
\text { products. }\end{array}$ & 0.032 & 0.064 & -0.037 & 0.507 & 0.614 & Unrelated \\
\hline $\begin{array}{l}\text { 4. Convenient payment method (cash and } \\
\text { credit card) }\end{array}$ & 0.026 & 0.063 & 0.027 & 0.416 & 0.678 & Unrelated \\
\hline 5. Various price levels available & 0.109 & 0.062 & 0.117 & 1.772 & 0.08 & Unrelated \\
\hline Place & & & & & & Unrelated \\
\hline $\begin{array}{l}\text { 1. Shops are located in a convenient } \\
\text { location. }\end{array}$ & 0.008 & 0.057 & -0.009 & 0.136 & 0.892 & Unrelated \\
\hline $\begin{array}{l}\text { 2. Many shops available as choices are } \\
\text { located in big department store. }\end{array}$ & 0.203 & 0.071 & 0.218 & 2.874 & $0.005^{*}$ & Related \\
\hline 3. Modern design of shops. & 0.02 & 0.074 & 0.019 & 0.265 & 0.792 & Unrelated \\
\hline 4. Sufficient parking space available. & 0.294 & 0.078 & 0.291 & 3.75 & $0.000^{*}$ & Related \\
\hline 5. Shops also have other services. & 0.088 & 0.083 & 0.088 & 1.059 & 0.292 & Unrelated \\
\hline 6. Shops open everyday. & 0.161 & 0.084 & 0.166 & 1.92 & 0.058 & Unrelated \\
\hline $\begin{array}{l}\text { 7. There are showcases in the shop and } \\
\text { easy to choose products. }\end{array}$ & 0.099 & 0.1 & 0.093 & 0.994 & 0.323 & Unrelated \\
\hline $\begin{array}{l}\text { 8. Problem products bought can later be } \\
\text { changed. }\end{array}$ & 0.013 & 0.093 & 0.012 & 0.141 & 0.888 & Unrelated \\
\hline 9. Sufficient product stocks. & 0.061 & 0.085 & 0.064 & 0.718 & 0.474 & Unrelated \\
\hline $\begin{array}{l}\text { 10. Order can be done through website. } \\
\text { Promotion }\end{array}$ & 0.144 & 0.079 & 0.142 & 1.832 & 0.07 & Unrelated \\
\hline $\begin{array}{l}\text { 1. There are promotions via medias such } \\
\text { as website. }\end{array}$ & 0.08 & 0.086 & 0.077 & 0.936 & 0.352 & Unrelated \\
\hline $\begin{array}{l}\text { 2. Premiums are given for volume } \\
\text { purchase. }\end{array}$ & 0.048 & 0.098 & 0.048 & 0.492 & 0.624 & Unrelated \\
\hline 3. There are coupons for lucky draw. & 0.164 & 0.1 & 0.152 & 1.648 & 0.103 & Unrelated \\
\hline 4. Price discount promotion available. & 0.005 & 0.117 & 0.004 & 0.039 & 0.969 & Unrelated \\
\hline 5. There are promotions continuously & 0.28 & 0.105 & 0.259 & 2.67 & $.009 *$ & Related \\
\hline 6. There are product introduction and & 0.693 & 0.102 & 0.658 & 6.793 & $.000^{*}$ & Related \\
\hline
\end{tabular}




\begin{tabular}{|c|c|c|c|c|c|c|}
\hline 7. There are documents of product & .097 & .246 & .110 & .393 & .695 & Unrelated \\
\hline $\begin{array}{l}\text { 8. Level of satisfaction in promotional } \\
\text { activities }\end{array}$ & .118 & .204 & .142 & .580 & .564 & Unrelated \\
\hline
\end{tabular}

*Significance level 0.05

\section{Conclusion, Discussion and Recommendation}

\subsection{Conclusion}

The research on factors affecting consumer behavior for buying accessories aims to evaluate effects of marketing mix and to study consumer's buying behavior for accessories products. This quantitative study has independent variables which are gender, age, marital status, education, monthly income, and number of accessories as well as marketing mix including product, price, place, and promotion. Dependent variable is consumer behavior in choosing accessories. Questionnaires were used as a tool in this study and statistics applied were percentage, mean, standard deviation, Chi-square, and regression analysis.

\subsection{Recommendation for Further Studies}

This study involves consumer behavior in purchasing accessories products in general. If there is any future study on this topic, it should consider each type of accessories deeply such as Ruby, Sapphire, Corundum, and Platinum to have more precise findings.

\section{Reference}

[1] Natnaree Tangtrakul. (2012). Factors that have Influences on Thai Tourists' Purchasing Behavior for Wooden Souvenir Products. Case Study of Hua Dong Village, Soongmen District, Phrae Province. Independent study. Bachelor's of Business Administration. (Tourism and Hotel Management). Faculty of Business, Economic, and Communication. Naresuan University.

[2] Siriwan Serirat. (2001). Consumer Behavior. Bangkok: Wisitwattana.

[3] Siriwan Serirat and Amornsak Boonrueng. (2003). Modern Marketing Management. Bangkok: Diamond in business world.

[4] Siriwan Serirat et al. (1998). Business Research. Bangkok: Diamond in business world.

[5] Thanin Trairak. (2011). Marketing Factors that have Influences on Customers in Bangkok's

[6] Purchasing Decision for Products in Man-U Shop. Independent study. Marketing Major. Faculty of Business Administration. Rajamangala University of Technology Thanyaburi.

[7] Thongchai Santiwong. (1997). Consumer Behavior. Bangkok: Thaiwattanapanich

[8] Wilaiwan Sriamphai. (2012). Factors that have Influences on Buyers' Purchasing Decision of Products from Ancient Market Baan Sakaekrang (Rongya Alley Walking Street) Uthai Thani Province. Independent study. Master of Business Administration. International Business major, Faculty of Business Administration. Rajamangala University of Technology Thanyaburi. 